\title{
AS RELAÇÕES ENTRE TRADUÇÃO E ADAPTAÇÃO E AS VARIAÇÕES DA IDENTIDADE NEGRA EM $A$ CABANA DO PAI TOMÁS, DE HARRIET BEECHER STOWE
}

\section{RELATIONSHIPS BETWEEN TRANSLATION AND ADAPTATION AND BLACK IDENTITY VARIATION IN UNCLE TOM'S CABIN, BY HARRIET BEECHER STOWE}

\author{
Thaís Polegato de Sousa* \\ Lauro Maia Amorim
}

\section{RESUMO}

Este artigo propõe-se a discutir as fronteiras entre tradução e adaptação literária, utilizandose, para isso, das observações feitas a partir da comparação entre uma tradução e duas adaptações da obra A Cabana do Pai Tomás (Uncle Tom's Cabin), de Harriet Beecher Stowe. Levando-se em consideração critérios como a época de publicação de cada reescrita e a ideologia declarada pelas editoras, levantamos trechos problemáticos que exigiam que tradutor ou adaptador apresentassem algum tipo de solução, e com isso demonstramos que os limites entre as duas práticas, apesar do que se poderia esperar, não são tão claros e absolutos. Foram destacados também fragmentos que expunham a imagem construída, em cada reescrita, dos personagens negros e, por extensão, da identidade negra, teorizando se por trás dessas imagens haveria uma relação com o rótulo de tradução ou adaptação, ou se esse constructo estaria mais ligado a outros fatores. O que se observou foi uma relação mais sólida entre identidade e contexto histórico e ideologia do que entre identidade e rótulos, confirmando assim a importância de fatores extratextuais nas reescritas analisadas e a fragilidade da oposição que tradicionalmente separa tradução de adaptação.

Palavras-chave: Tradução; Adaptação; Identidade Negra.

\section{ABSTRACT}

This article aims to discuss the limits between translation and adaptation of literature. With such purpose in mind, we have developed a reflection built upon the comparison between

\footnotetext{
* Universidade Estadual Paulista, UNESP, São José do Rio Preto (SP), Brasil. polegatosousa@gmail.

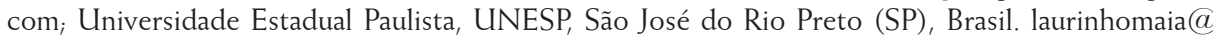
gmail.com

Thaís Polegato de Sousa agradece à Fapesp (Processo 2013/11899-4) pelo apoio financeiro recebido durante a pesquisa de iniciação científica que deu origem a algumas das reflexões apresentadas neste artigo, e à CAPES, pela concessão de bolsa para a pesquisa de mestrado atualmente em desenvolvimento.
} 
one translation and two adaptations of Uncle Tom's Cabin (A Cabana do Pai Tomás), by Harriet Beecher Stowe into Brazilian Portuguese. We have kept in sight a range of criteria - such as when these pieces were published and what is the declared ideology of the publishing houses involved - and analyzed some problematic excerpts, expecting that some sort of resolution was presented by the translator or adaptor. It became clear, with such proceedings, that the limits between translation and adaptation are not so obvious or absolutely clear-cut. We have also analyzed passages that expose how each piece portrayed black characters, and, therefore, black identity. We wonder if there is a correlation between translation or adaptation and such racial portraits or whether this construct is more distinctively related to other elements. We observed a solid relationship between identity and historical context and ideology, rather than a relationship between identity and the kind of text published. This confirms the importance of elements external to the text itself in our corpus and the fragility underling the opposition that traditionally separates translation from adaptation.

Keywords: Translation; Rewriting; Black Identity.

\section{INTRODUÇÃO: TRADUÇÃO, ADAPTAÇÃO E REESCRITA}

Por sua natureza multifacetada e mutável, tradução e adaptação não admitem definições absolutas. Os dois processos se confundem tanto ao longo da história dos Estudos da Tradução quanto na prática, e embora muitos autores defendam que os dois são completamente separados, o que se observa é que muitas técnicas e escolhas de estilo são comuns a ambos.

A visão mais tradicional, compartilhada pelo senso comum, encoraja a dicotomia entre as duas práticas, com a tradução sendo considerada a versão fiel e completa, e a adaptação sendo considerada a versão infiel e simplificadora. Krebs (2012), no entanto, percebe tantas semelhanças entre tradução e adaptação que se posiciona contrariamente à separação dessas duas áreas. Amorim (2005), embora não se posicione tão radicalmente, também questiona essa bipolarização. $\mathrm{O}$ autor afirma que critérios típicos, como fidelidade e transformação, variam entre autores, sendo pouco confiáveis para separar as atividades que, em sua perspectiva, têm muitos pontos em comum e cujos limites não são sempre claros e imutáveis.

A compreensão do que seria adaptação, bem como a compreensão do que seria tradução e das fronteiras entre elas, é uma discussão baseada amplamente em reflexões teóricas, mas poucas vezes levada para o plano das análises práticas, em nosso entender uma etapa essencial para construir esse conhecimento. Quando se aventuram no campo das análises práticas, os resultados obtidos pelos autores que o fazem são diversos. Bertin (2011), que compara seis traduções e quatro adaptações de A Tempestade, de Shakespeare, atém-se às percepções tradicionais e conclui que a tradução é fiel e a adaptação, transgressora. Ferreira e Silva (2011), por sua vez, comparam uma tradução e uma tradução-adaptação de Tales of the 
Grotesque and Arabesque, de Edgar Alan Poe, e procuram, ao compará-las entre si e com o original, esclarecer com base na prática as diferenças entre tradução e adaptação. $\mathrm{O}$ que as autoras observam, no entanto, é que recursos tipicamente atribuídos à adaptação, e muitas vezes tidos como erros ou simplificações por uma perspectiva mais tradicional, são utilizados também na tradução, de forma que a fronteira entre as duas práticas se esvanecem. Entre os procedimentos comuns observados por Ferreira e Silva (2011) estão omissões, acréscimos, mudanças de ordem sintática e de ênfase.

Amorim (2005) compara três traduções e uma adaptação de Alice's adventures in Wonderland, de Lewis Carroll, e uma tradução e uma adaptação de Kim, de Rudyard Kipling. Em sua análise sobre as reescrituras de Alice's adventures in Wonderland, Amorim (2005) focaliza as estratégias que cada tradutor ou adaptador utiliza em trechos problemáticos, e demonstra que muitas vezes a concepção tradicional de que a tradução seria mais fiel e provocaria menos mudanças, e a adaptação seria mais livre, mais criativa, é rompida pelas opções empregadas nas reescrituras, que por vezes tornariam as traduções mais ousadas, enquanto as adaptações escolheriam caminhos mais conservadores. No caso de Kim, Amorim (2005), além de observar os recursos utilizados pelo tradutor e pela adaptadora, enfatiza o modo como as reescritas apresentam a Índia e Kipling. Ele aponta que as opções tradutórias guiam o leitor para determinadas interpretações do país e do autor original: a adaptação construiria a imagem de uma Índia sem conflitos, provavelmente tentando relatar o que adaptador e editora acreditaram ser a perspectiva de Kipling; a tradução, por outro lado, embora possa ser mais conservadora, chega a acentuar a visão imperialista do original.

Azenha e Moreira (2012) comparam trechos da reescrita A Saga de Siegfried, de Tatiana Belinky, com os trechos correspondentes de Deutsche Heldensagen traduzidos para o português pelos autores e confirmam que existem diferenças significativas entre a adaptação de Belinky, feita tendo em vista as expectativas de um público leitor e de uma editora, e a tradução oferecida por eles mesmos, feita com fins acadêmicos, sem interferência de fatores externos ao tradutor. No entanto, apontam que as semelhanças, do ponto de vista da função, também são muitas; portanto, não se arriscam a indicar quais critérios de separação entre tradução e adaptação são reais ou definitivos.

Rodrigues (2002) levanta a hipótese de que, a depender do teórico, os mesmos procedimentos são aceitáveis ou não, dependendo da classificação entre tradução ou adaptação recebida pela obra. Pode-se ir além: mais do que serem aceitáveis, certos procedimentos são associados à tradução e outros são associados à 
adaptação pelo senso comum, de modo que o público leitor espera que as primeiras sejam fiéis, integrais, e que as segundas sejam criativas, livres. O que se observa na prática é que esses procedimentos, até certo ponto, se entrecruzam, confirmando que as duas práticas são mais próximas do que se imagina.

\section{ENTRE 0 ADAPTAR E 0 TRADUZIR, A FIGURA DO AFRODESCENDENTE EM QUESTÃO}

O que norteia nossa pesquisa é avaliar de que modo se efetivam as relações entre tradução e adaptação no campo da divulgação de literatura estrangeira, tendose em vista não apenas a construção das identidades dessas duas práticas, mas, também, as identidades de personagens negras. Do mesmo modo que os limites entre tradução e adaptação transformam-se de acordo com diversos fatores, a forma como é percebida a identidade racial no imaginário de um país é passível de mudanças. E isso parece estar ocorrendo no Brasil.

Inicialmente, como aponta Magnoli (2009), o mito de origem de nosso país, dos três rios que se unem, simbolizando a união do nativo, do branco e do negro, valorizaria a figura do mestiço. Já o modelo racial norte-americano, com a ideia de raças separadas, estaria sendo importada para o Brasil, suplantando as identidades raciais precárias de nosso pais e a valorização de uma identidade intermediária que não seria necessariamente racial. Magnoli $(2009$, p.16) é contrário a essa importação, pois, de acordo com ele, "a raça é fruto do poder de Estado que rejeita o princípio da igualdade entre os cidadãos", e "o princípio da igualdade política encontra amparo na poderosa narrativa identitária da mestiçagem, que borrou as fronteiras de raça", afirmações que justificariam sua postura a favor da mestiçagem.

Munanga (2004), por sua vez, posiciona-se contra a mestiçagem no Brasil, pois a considera um mecanismo para enfraquecer os movimentos que lutam pelos direitos da população negra. Ele discorda da visão de que, a despeito da forma como se deu o encontro entre portugueses, indígenas e africanos, a sociedade nascente desse encontro era uma mistura positiva de raças e culturas. Para Munanga (2004, p.108), uma "nova etnia nacional" seriam os restos de uma unificação política que oprimiu as identidades étnicas discrepantes e reprimiu tendências separatistas.

Munanga (2004) afirma que essa visão assimiladora, pregada pelos que defendem uma identidade nacional mestiça, é combatida pelos movimentos negros atuais, que buscam a construção de uma identidade negra, voltando às origens culturais e históricas. Ele afirma que o modelo de racismo no Brasil é universalista, 
ou seja, ele buscaria assimilar o diferente na raça e na cultura hegemônica, no que o autor considera uma tentativa de apagamento completo da diferença através da homogeneização, apagamento esse que deveria se realizar pela miscigenação. $\mathrm{O}$ autor aponta que a mestiçagem teria sido o primeiro passo em direção a um embranquecimento eugênico de planejamento governamental.

Para Munanga (2004), a mestiçagem não conseguiu resolver os conflitos causados pela hierarquização de raças no Brasil; ela apenas manteria esses conflitos em estado latente. $\mathrm{O}$ autor afirma que a ideologia da mestiçagem, embora venha se polarizando, ainda continua forte no imaginário brasileiro, e o mestiço continuaria tendo sua identidade, seja como negro ou como mestiço, adiada pelo sonho do branqueamento.

Magnoli (2009) e Munanga (2004) ilustram posicionamentos opostos sobre a questão racial no Brasil: enquanto um valoriza a mestiçagem, o outro valoriza a distinção racial. Essas duas perspectivas refletem os dois principais pensamentos raciais conflitantes do Brasil atual, mas não estão livres de críticas. A crença de Magnoli (2009) de que a igualdade seria alcançada sem medidas impostas "de cima para baixo", pela miscigenação, parece excessivamente otimista. Por outro lado, Munanga (2004) parece invalidar a identidade mestiça, que embora não seja a solução para todos os problemas raciais, como parece crer Magnoli (2009), é uma identidade válida, e uma realidade para muitos brasileiros.

No momento atual, não há vencedor entre esses dois posicionamentos discordantes. O momento é de uma coexistência tensa, que tende, cedo ou tarde, a pender para um dos lados. No entanto, por enquanto, ambos seguem lutando por um lugar no ideário racial brasileiro, e até que o conflito se resolva, os dois estariam aptos a influenciar a percepção sobre a identidade negra no Brasil em todos os âmbitos, inclusive no da tradução e da adaptação de produções literárias que, sendo ou não de autores afrodescendentes, refletem, em alguma medida, sobre a situação dos negros na nossa sociedade.

Sob essa perspectiva, A Cabana do Pai Tomás é um objeto de análise rico: não só trata da escravidão nos EUA, fornecendo amplo campo de análise para conflitos raciais, como também foi amplamente publicado no Brasil ao longo dos anos. Sua autora, Harriet Beecher Stowe, começou a escrever contos aos 23 anos. Em 1843, publicou sua primeira antologia de contos, The Mayflower, e, em 1845, seu primeiro folheto abolicionista, Immediate Emancipation. Em 1850, começou a escrever o que seria seu romance de maior sucesso, Uncle Tom's Cabin, que foi publicado em formato de folhetim entre 1851 e 1852, e posteriormente em forma de livro, em 1852. Harriet Beecher Stowe faleceu em 1896, deixando mais de 15 romances, além de contos e 
ensaios, sem nunca ter conseguido reproduzir sucesso comparável ao de Uncle Tom's Cabin.

Uncle Tom's Cabin conta a história de dois escravos de uma fazenda no Kentucky, Eliza e Tom, que tomam decisões opostas quando seu dono, o Sr. Shelby, decide vender alguns de seus escravos para pagar dívidas: Eliza foge com seu filho Harry, que o dono pretendia vender, e Tom decide ficar e ser vendido, separando-se assim de sua esposa, Cloé, e de seus filhos, para que outros escravos não tenham que tomar seu lugar. Ao longo do livro, Eliza é caçada, mas termina triunfante junto de seu marido e filho, e reencontra a mãe, também ex-escrava, de forma que a família encontra um final feliz; Tom, por sua vez, é vendido diversas vezes, encontrando condições cada vez mais degradantes e testemunhando diversas tragédias ao longo de seu caminho, até que por fim é assassinado por seu último proprietário momentos antes de ser recuperado pelo filho de seu primeiro dono.

A influência associada à Harriet Beecher Stowe e a Uncle Tom's Cabin imediatamente após a publicação deste não foi insignificante. Mais de um livro foi publicado na tentativa de desacreditar seu teor, tentando mostrar uma relação idílica entre senhor e escravo. Anedotas contam que Uncle Tom's Cabin e sua autora foram responsabilizados pela deflagração da guerra civil norte-americana pelo presidente norte-americano Abraham Lincoln. As discussões em torno dessa obra, no entanto, não se resumem a esse período da história estadunidense, e têm relevância até hoje: quando criou o personagem Tom, Stowe não parecia estar tentando construir um herói, mas sim um mártir. Sua caracterização se torna problemática, porém, pela ausência (ou, pelo menos, pela invisibilidade) de personagens negros no papel de heróis que sejam tão emblemáticos na cultura norte-americana quanto Tom se tornou. E isso é válido também para as várias culturas para as quais Uncle Tom's Cabin foi exportado, especialmente culturas em que ocorreu a escravidão dos negros, como a brasileira.

Foram escolhidas três reescrituras dessa obra para análise comparativa: a adaptação sem indicação de adaptador, de 1964, da Edições Paulinas; a adaptação de Evangelista Prado, de 1969, do Clube do Livro; e a tradução de Nélia Maria Pinheiro Padilha von Tempski-Silka, de 2012, da Juruá Editora. Elas foram escolhidas especialmente pela análise histórica que possibilitam, dado que duas delas foram lançadas antes da instauração do Estatuto da Igualdade Racial, de 2005, e uma delas após esse estatuto, sendo, dessa forma, ideais para a comparação da construção da imagem do negro, além de possibilitarem a comparação entre adaptação e tradução.

Outro fator importante foi o perfil das editoras que lançaram essas reescrituras, em especial nas adaptações escolhidas: a Edições Paulinas, hoje conhecida como 
Paulus Editora, afirma claramente em seu site que sua função é evangelizar, mudar a sociedade e guiá-la por um caminho que considera mais humano e cristão, e não há motivos para crer que suas intenções fossem diferentes no momento em que publicou A Cabana do Pai Tomás; o Clube do Livro se apresenta como uma "semeadora" de livros, uma instituição que faz "o povo pensar", em suas próprias palavras, ou seja, uma formadora de opiniões. Contudo, tanto pela escolha das obras quanto pelas práticas observadas por Milton (2009) em relação a essa editora, parece-nos evidente que, mais do que fomentar o pensamento crítico, o Clube do Livro procura direcionar o pensamento de seus leitores para caminhos específicos que lhe convêm; a Juruá Editora se apresenta como uma editora voltada à nova identidade racial brasileira, que viria, em tese, paulatinamente substituir a narrativa da mestiçagem. A autora de seu prefácio, Angela Gilliam, é uma antropóloga especialista em questões de gênero, raça e classe, e é a partir desse ponto de vista que ela disserta sobre as qualidades e defeitos da obra. Essas informações, aliadas àquelas trazidas nas orelhas do livro e na nota introdutória da tradutora, são a marca do esforço que a editora faz no sentido de mostrar-se séria e competente.

Ao começarmos a análise dos livros selecionados, logo de início foi observada uma diferença substancial entre as três reescrituras: as duas adaptações eram significativamente menores que a tradução - e embora não fosse possível colocálas lado a lado com o original, dado que este se encontra em meio eletrônico, poderíamos supor que esse também se apresentaria maior, caso estivesse impresso.

A diferença é significativa: a tradução da Juruá Editora apresenta 474 páginas, enquanto a adaptação da Edições Paulinas tem 202 páginas e a adaptação do Clube do Livro, 153 páginas. Enquanto o original e a tradução apresentam 45 capítulos, nas duas adaptações esse número diminui quase pela metade: 25 capítulos. Podemos observar também, após a leitura individual de cada uma das obras, que a maioria dos capítulos retirados das adaptações foram os que narravam a fuga de George e Eliza Harris, concentrando a história de fato na personagem de Tomás. Apenas a tradução parece seguir a linha de enredo do original com grande proximidade.

Dadas essas distinções, as diferentes origens, ideologias e objetivos de cada editora, e a própria natureza transformadora dos processos de tradução e de adaptação, podemos esperar que original, tradução e adaptações apresentem diferenças significativas entre $\mathbf{s i}_{i}$ mais do que observar as possíveis diferenças e semelhanças, no entanto, interessa-nos constatar de que forma elas afetam as fronteiras entre processos de tradução e de adaptação e a forma como é reconstruída a identidade negra nas reescrituras. 
Não iremos, dadas as limitações de espaço, exibir todos os trechos que foram analisados. Mostraremos apenas alguns dos casos mais ilustrativos das questões que aqui nos interessam (desafios tradutórios e a forma como são retratados os personagens negros), começando pela seguinte passagem, em que o Sr. Shelby manda que o pequeno Harry, filho de Eliza e George Harris, dance para um convidado:

Tabela 1: Shelby manda Harry dançar

\begin{tabular}{|c|c|c|c|}
\hline $\begin{array}{l}\text { Uncle Tom's Cabin } \\
\text { (original - 1852) }\end{array}$ & $\begin{array}{l}\text { A Cabana do Pai } \\
\text { Tomás (adaptação } \\
\text { Edições Paulinas; } \\
\text { 1964; sem indicação } \\
\text { de adaptador) }\end{array}$ & $\begin{array}{l}\text { A Cabana do Pai } \\
\text { Tomás (adaptação } \\
\text { Clube do Livro; } \\
\text { 1969; adaptação de } \\
\text { Evangelista Prado) }\end{array}$ & $\begin{array}{l}\text { A Cabana do Pai } \\
\text { Tomás (tradução } \\
\text { Juruá Editora; 2012; } \\
\text { tradução de Nélia } \\
\text { Maria Pinheiro } \\
\text { Padilha von Tempski- } \\
\text { Silka) }\end{array}$ \\
\hline $\begin{array}{l}\text { "Hulloa, Jim Crow!" } \\
\text { said Mr. Shelby, } \\
\text { whistling, and } \\
\text { snapping a bunch of } \\
\text { raisins towards him, } \\
\text { "pock that up, now!" }\end{array}$ & $\begin{array}{l}\text { - Alô, Jim Crow, } \\
\text { venha cá - disse o sr. } \\
\text { Shelby, afagando-lhe a } \\
\text { cabeça: }\end{array}$ & $\begin{array}{l}\text { - Alô, Jim Crow, } \\
\text { venha cá - disse o sr. } \\
\text { Shelby, afagando-lhe a } \\
\text { cabeça: }\end{array}$ & $\begin{array}{l}\text { - Olá, Jim Crow! - } \\
\text { disse o Sr. Shelby, } \\
\text { assobiando e jogando } \\
\text { um ramo de parreira } \\
\text { em sua direção - pega } \\
\text { isso, já! }\end{array}$ \\
\hline $\begin{array}{l}\text { The child scampered, } \\
\text { with all his little } \\
\text { strength, after the } \\
\text { prize, while his master } \\
\text { laughed. }\end{array}$ & & & $\begin{array}{l}\text { A criança lançou- } \\
\text { se, com toda a sua } \\
\text { pequena força, atrás do } \\
\text { prêmio, enquanto seu } \\
\text { amo ria. }\end{array}$ \\
\hline $\begin{array}{l}\text { "Come here, Jim } \\
\text { Crow," said he. The } \\
\text { child came up, and } \\
\text { the master patted } \\
\text { the curly head, and } \\
\text { chucked him under } \\
\text { the chin. }\end{array}$ & & & $\begin{array}{l}\text { - Venha aqui, Jim } \\
\text { Crow - disse ele. A } \\
\text { criança chegou perto } \\
\text { e o amo passou a } \\
\text { mão em seus cabelos } \\
\text { encaracolados, e } \\
\text { apertou-lhe o queixo. }\end{array}$ \\
\hline $\begin{array}{l}\text { "Now, Jim, show this } \\
\text { gentleman how you } \\
\text { can dance and sing." }\end{array}$ & $\begin{array}{l}\text { - Mostre a este } \\
\text { senhor como você } \\
\text { sabe cantar e dançar. }\end{array}$ & $\begin{array}{l}\text { - Mostre a este senhor } \\
\text { como você sabe cantar } \\
\text { e dançar. }\end{array}$ & $\begin{array}{l}\text { - Agora, Jim, mostre a } \\
\text { esse senhor como você } \\
\text { sabe dançar e cantar. }\end{array}$ \\
\hline
\end{tabular}




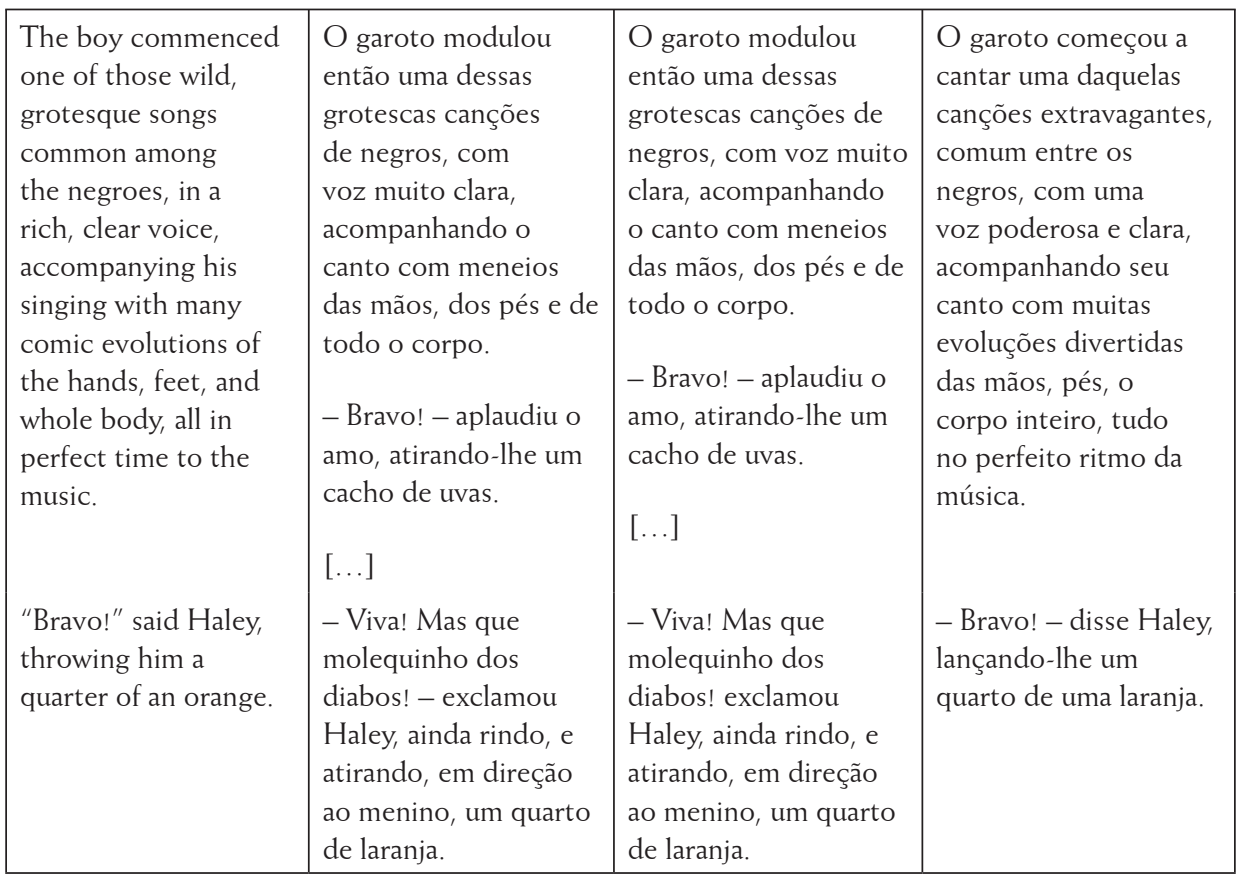

Nesse trecho, temos, no original, a seguinte sequência de acontecimentos: um menino entra na sala; o Sr. Shelby lhe dá algumas uvas; o Sr. Shelby manda que ele dance e cante; Haley lhe dá um pedaço de laranja. Posteriormente, em trecho que não está presente aqui, o Sr. Shelby manda que o menino imite um velho com reumatismo.

Esse trecho mostra-se interessante por ser a primeira interação entre um escravo e seu dono mostrada no livro, justamente entre um senhor caracterizado até então como "bom", "humano" e "cavalheiresco", e um menino que, apesar de escravo, aparenta confiança suficiente para ir e vir dentro da casa de seu dono e está acostumado a ser bem tratado. No entanto, essa interação não se parece tanto com a de um protetor e um protegido, mas com a de um homem e seu bicho de estimação, pois, logo que o menino chega, o Sr. Shelby manda que ele faça uma série de truques, e lhe dá pequenas recompensas. Essa perspectiva menos que idílica sobre a relação entre donos e escravos é reforçada diversas vezes durante o livro. Também acontece uma "dança" que seria relacionada à "raça" negra pelo narrador, reforçando o estereótipo do negro criativo, sensível, intuitivo.

A tradução não faz cortes a essa cena, e a adaptação da Edições Paulinas, embora mude a ordem das ações dos personagens, de certa maneira também não, embora mais uma vez resuma os acontecimentos. É mais digno de nota que 
todas as versões mantenham a expressão "Jim Crow", um modo pejorativo de se dirigir a pessoas negras nos EUA, e que foi utilizada inclusive para apelidar as leis segregacionistas desse país. No Brasil, não ocorre tal equivalência, e o apelido poderia ser entendido como algo carinhoso ou brincalhão, quando na realidade estaria mais próximo de algo como a "macaca de carvão" de Monteiro Lobato.

É interessante notar também que é a perspectiva do narrador (possivelmente refletindo uma ideologia da autora da obra) que classifica a dança do menino como grotesque, termo que é mantido nas adaptações e que revela certo preconceito velado, pois coloca o menino negro no lugar do diferente e do outro excluído, sob uma luz negativa. Na tradução da Juruá, o termo utilizado é "extravagante", que atenua essa "exotização" do personagem, e o termo wild é retirado, ocultando uma suposta "selvageria" que seria característica da "raça" negra no original. A mesma técnica é utilizada, na tradução, para atenuar o termo comic, que implica uma diversão às custas do pequeno escravo no original, optando-se na tradução pelo termo "divertido", que parece ter uma carga semântica mais leve, como se a diversão incluísse a todos no recinto. Na adaptação da Edições Paulinas (reproduzida integralmente mais uma vez pelo Clube do Livro), qualquer menção a comic é retirada, e o termo grotesque é traduzido literalmente por "grotesco".

Outro trecho interessante é o analisado abaixo, em que é mencionado um dos pontos mais polêmicos da obra, e um dos que mais merecem destaque, especialmente por ser muitas vezes ignorado: o abuso sexual a que as escravas eram submetidas por seus donos:

Tabela 2: Os pais de George

\begin{tabular}{|l|l|l|l|}
\hline $\begin{array}{l}\text { Uncle Tom's Cabin } \\
\text { (original - 1852) }\end{array}$ & $\begin{array}{l}\text { A Cabana do Pai Tomás } \\
\text { (adaptação Edições } \\
\text { Paulinas; 1964; sem } \\
\text { indicação de adaptador) }\end{array}$ & $\begin{array}{l}\text { A Cabana do Pai Tomás } \\
\text { (adaptação Clube do } \\
\text { Livro; 1969; adaptação } \\
\text { de Evangelista Prado) }\end{array}$ & $\begin{array}{l}\text { A Cabana do Pai Tomás } \\
\text { (tradução Juruá Editora; } \\
\text { 2012; tradução de Nélia } \\
\text { Maria Pinheiro Padilha } \\
\text { von Tempski-Silka) }\end{array}$ \\
\hline $\begin{array}{l}\text { We remark, en passant, } \\
\text { that George was, by } \\
\text { his father's side, of } \\
\text { white descent. His } \\
\text { mother was one of } \\
\text { those unfortunates of } \\
\text { her race, marked out by } \\
\text { personal beauty to be } \\
\text { the slave of the passions } \\
\text { of her possessor, and } \\
\text { the mother of children } \\
\text { who may never know a } \\
\text { father. }\end{array}$ & Trecho retirado & Trecho retirado & $\begin{array}{l}\text { Observamos, en passant, } \\
\text { que George era, do lado } \\
\text { do pai, descendente de } \\
\text { brancos. Sua mãe era } \\
\text { uma dessas infelizes de } \\
\text { sua raça, marcada pela } \\
\text { beleza pessoal, para ser } \\
\text { escrava das paixões do } \\
\text { seu proprietário, e mãe } \\
\text { de filhos que nunca } \\
\text { conheceriam pai. }\end{array}$ \\
\hline
\end{tabular}


Acima, temos uma das primeiras passagens que apontam para o abuso sofrido pelas escravas. Podemos imaginar que os detratores da obra de Stowe os que se levantaram contra Uncle Tom's Cabin à época de sua publicação clamando que o retrato descrito por Stowe era o falso, e as relações idílicas entre escravos e senhores a verdade - teriam negado firmemente tais acontecimentos, atribuindo-os a um estereótipo da "raça" negra: o da promiscuidade. No entanto, a autora deixa claro, nesse trecho e em muitos outros, que tais relações ocorriam, e que elas eram forçadas. A despeito de seu hábito de reforçar estereótipos relacionados aos negros, e algumas vezes também aos brancos, nesse ponto Stowe não falha, e a lenda da hipersexualidade da mulher negra é firmemente negada.

Essa postura de Stowe levanta, porém, mais de um ponto polêmico; além de expor o abuso sexual, a autora mostra a presença de mestiços na sociedade americana. Há também no romance termos específicos, hoje em desuso, para designar pessoas de origem mista: quadroon e mulatto, que fariam referência, respectivamente, a indivíduos com três quartos de "sangue branco" e um quarto de "sangue negro", e metade de "sangue branco" e metade de "sangue negro". George Harris parece pertencer à segunda classificação.

Todas essas questões são apagadas nas adaptações, assim como os possíveis conflitos causados por elas. Só podemos especular se o corte se deu por motivo de espaço; se a Edições Paulinas se opõe a expor a violência contra as mulheres em suas obras e o Clube do Livro, automaticamente, também descartou esse trecho, já que ele é uma cópia praticamente exata da versão da Edições Paulinas; ou se a questão do abuso, que com certeza também ocorreu no Brasil, seria causadora de incômodos em um país que supostamente abraça a mestiçagem; ou, ainda, se o relato dos abusos, não estando relacionados diretamente a Tomás e sua religião, teriam sido considerados desnecessários.

$\mathrm{Na}$ tradução, essas questões são trazidas à tona na mesma medida em que no original, e temos também a questão do uso do termo francês en passant. À época de sua publicação, o francês era a língua internacional, e é razoável pensar que o entendimento dessa expressão não seria desafio para o leitor de então. No entanto, na atualidade, a língua internacional é o inglês, e ao optar por manter a expressão do original, a tradução poderia causar problemas de compreensão para seu leitor. Isso é resolvido por uma nota do tradutor, que explicita que a expressão poderia ser traduzida no português por "de passagem".

Outro trecho interessante é o período em que Eliza fica escondida em um povoado quaker: 
Tabela 3: Conversa entre Eliza e quaker

\begin{tabular}{|c|c|c|c|}
\hline $\begin{array}{l}\text { Uncle Tom's Cabin } \\
\text { (original - 1852) }\end{array}$ & $\begin{array}{l}\text { A Cabana do Pai } \\
\text { Tomás (adaptação } \\
\text { Edições Paulinas; } \\
\text { 1964; sem indicação de } \\
\text { adaptador) }\end{array}$ & $\begin{array}{l}\text { A Cabana do Pai } \\
\text { Tomás (adaptação } \\
\text { Clube do Livro; } \\
\text { 1969; adaptação de } \\
\text { Evangelista Prado) }\end{array}$ & $\begin{array}{l}\text { A Cabana do Pai } \\
\text { Tomás (tradução } \\
\text { Juruá Editora; 2012; } \\
\text { tradução de Nélia } \\
\text { Maria Pinheiro } \\
\text { Padilha von Tempski- } \\
\text { Silka) }\end{array}$ \\
\hline $\begin{array}{l}\text { "And so thee still } \\
\text { thinks of going to } \\
\text { Canada, Eliza?" she } \\
\text { said, as she was quietly } \\
\text { looking over her } \\
\text { peaches. } \\
\text { "Yes, ma'am," said } \\
\text { Eliza, firmly. "I must } \\
\text { go onward. I dare not } \\
\text { stop." } \\
\\
\text { "And what'll thee do, } \\
\text { when thee gets there? } \\
\text { Thee must think about } \\
\text { that, my daughter." }\end{array}$ & Trecho retirado & Trecho retirado & $\begin{array}{l}\text { - E então, você está } \\
\text { pensando em ir para o } \\
\text { Canadá, Eliza? - disse } \\
\text { ela, enquanto tratava } \\
\text { calmamente de seus } \\
\text { pêssegos. } \\
\text { - Sim, madame - disse } \\
\text { com firmeza Eliza. } \\
\text { - Preciso continuar. } \\
\text { Nem penso em } \\
\text { interromper o meu } \\
\text { caminho. } \\
\text { - E o que você irá } \\
\text { fazer, quando lá } \\
\text { chegar? Você precisa } \\
\text { pensar sobre isso, } \\
\text { minha filha. }\end{array}$ \\
\hline
\end{tabular}

Há algumas questões especialmente interessantes do ponto de vista tradutório nesse trecho: primeiramente, a linguagem utilizada pela quaker contrasta com a de Eliza; porém, diferente do que acontece com outros escravos ao longo do romance, não há incorreção gramatical nos diálogos, mas uma diferença em formalidade. A segunda pessoa, no inglês do século XIX, denotava informalidade, e era usada pelos quaker por conta de sua crença de que todos os seres humanos seriam iguais perante Deus, e que as hierarquias sociais seriam apenas uma criação humana, que eles rejeitam inclusive na fala. Já Eliza, que foi criada num espectro religioso mais rígido e era, até pouco tempo, uma escrava, ocupando uma posição social inferior, utiliza o formalíssimo ma’am.

$\mathrm{Na}$ tradução da Juruá, a linguagem é uniformizada, de forma que as nuances percebidas no original não são recriadas aqui. Nesse caso, isso ocorre, provavelmente, devido à impossibilidade de usar a segunda pessoa do português para esse efeito: ocorreria justamente o contrário, com o nível de formalidade da fala aumentando consideravelmente. Mas o respeito e polidez de ma’am é bem traduzido no termo 
"madame", sem acrescentar um efeito semântico de hierarquia, que ocorreria com a tradução consagrada desse termo, "senhora", relacionado à antiga dona de Eliza.

Outra questão interessante é a quaker chamar Eliza de my daughter. Essa expressão reforça a informalidade da falante, e o carinho que ela tem por Eliza. $\mathrm{Na}$ tradução, em que se optou por "minha filha", a informalidade está presente, mas o carinho não está, necessariamente, incluso, devido ao uso arraigado dessa expressão em português em diversos contextos.

As adaptações não trazem essa passagem. É possível que não fosse interessante para a Edições Paulinas mostrar uma organização religiosa sem hierarquias, e se o trecho foi retirado da adaptação de 1964, a reescritura do Clube do Livro muito provavelmente sequer encontrou algo para cortar.

No trecho abaixo, temos um exemplo de uma escrava, a esposa de Tomás, Cloé, que, ao invés de assimilar a ideologia que justificava a escravidão, acha brechas no sistema para servir a seus próprios interesses, na medida do possível:

Tabela 4: Conversa entre Cloé e Sra. Shelby

\begin{tabular}{|c|c|c|c|}
\hline $\begin{array}{l}\text { Uncle Tom's Cabin } \\
\text { (original - 1852) }\end{array}$ & $\begin{array}{l}\text { A Cabana do Pai } \\
\text { Tomás (adaptação } \\
\text { Edições Paulinas; } \\
\text { 1964; sem indicação } \\
\text { de adaptador) }\end{array}$ & $\begin{array}{l}\text { A Cabana do Pai } \\
\text { Tomás (adaptação } \\
\text { Clube do Livro; } \\
\text { 1969; adaptação de } \\
\text { Evangelista Prado) }\end{array}$ & $\begin{array}{l}\text { A Cabana do Pai } \\
\text { Tomás (tradução } \\
\text { Juruá Editora; } \\
2012 \text {; tradução } \\
\text { de Nélia Maria } \\
\text { Pinheiro Padilha von } \\
\text { Tempski-Silka) }\end{array}$ \\
\hline $\begin{array}{l}\text { "If Missis would come } \\
\text { and look at dis yer lot } \\
\text { o' poetry." }\end{array}$ & $\begin{array}{l}\text { Neste momento } \\
\text { a conversa foi } \\
\text { interrompida pela } \\
\text { aproximação de Cloé, } \\
\text { que vinha chamar a } \\
\text { ama sob pretexto de } \\
\text { consultá-la sobre a } \\
\text { compra de algumas } \\
\text { provisões. }\end{array}$ & $\begin{array}{l}\text { Neste momento, } \\
\text { a conversa foi } \\
\text { interrompida pela } \\
\text { aproximação de Cloé, } \\
\text { que vinha chamar a } \\
\text { ama sob pretexto de } \\
\text { consultá-la sobre a } \\
\text { compra de algumas } \\
\text { provisões. }\end{array}$ & $\begin{array}{l}\text { - Se a senhora } \\
\text { quiser vir dar uma } \\
\text { olhada nesse lote de } \\
\text { "aveias"... }\end{array}$ \\
\hline $\begin{array}{l}\text { Chloe had a particular } \\
\text { fancy for calling } \\
\text { poultry poetry, - } \\
\text { an application of } \\
\text { language in which } \\
\text { she always persisted, } \\
\text { notwithstanding } \\
\text { frequent corrections } \\
\text { and advisings from the } \\
\text { young members of the } \\
\text { family. }\end{array}$ & & & $\begin{array}{l}\text { Cloé tinha um } \\
\text { hábito singular de } \\
\text { chamar 'aves' de } \\
\text { 'aveias' - um uso de } \\
\text { linguagem no qual } \\
\text { ela sempre persistia, } \\
\text { não obstante as } \\
\text { frequentes correções } \\
\text { e advertências dos } \\
\text { membros jovens da } \\
\text { família. }\end{array}$ \\
\hline
\end{tabular}




\begin{tabular}{|l|l|l|}
\hline $\begin{array}{l}\text { "La sakes!" she would } \\
\text { say, "I can't see; } \text { one jis } \\
\text { good as turry, - poetry } \\
\text { suthin good, any how," } \\
\text { and so poetry Chloe } \\
\text { continued to call it. }\end{array}$ & & $\begin{array}{l}\text { - Ora essa! - ela } \\
\text { costumava dizer - } \\
\text { não vejo por que; } \\
\text { uma é tão boa quanto } \\
\text { a outra, aveia é tão } \\
\text { bom, de qualquer } \\
\text { modo - e assim Cloé } \\
\text { continuava a chamar } \\
\text { aves de aveias. }\end{array}$ \\
\hline
\end{tabular}

Nesse trecho, temos outra questão tradutória interessante: o trocadilho feito por Cloé entre poultry, que significa aves, e poetry, que significa poesia. A brincadeira, justificada pelo lugar social da escrava, pede por uma resolução nas reescrituras. A solução proposta pela adaptação da Edições Paulinas, e copiada pela versão do Clube do Livro, é de simplesmente retirar o trocadilho, resumindo, inclusive, grande parte dessa passagem. A solução proposta pela tradução da Juruá é mais surpreendente: o trocadilho é recriado em português a partir do elemento essencial, que seria "aves". Essa postura mostra-se mais criativa, por assim dizer, do que a solução oferecida pela adaptação, demonstrando que essa característica, tida como um elemento típico da adaptação, também pode ocorrer nas traduções.

No trecho abaixo, uma vez que está só com sua senhora, Cloé, que provavelmente percebeu que o Sr. Shelby não parece estar muito preocupado em comprar Tomás de volta, coloca em prática seu plano para, sozinha, ganhar o dinheiro para resgatá-lo:

Tabela 5: Cloé sugere ir trabalhar na confeitaria

\begin{tabular}{|c|c|c|c|}
\hline $\begin{array}{l}\text { Uncle Tom's Cabin } \\
\text { (original - 1852) }\end{array}$ & $\begin{array}{l}\text { A Cabana do Pai } \\
\text { Tomás (adaptação } \\
\text { Edições Paulinas; } \\
\text { 1964; sem indicação } \\
\text { de adaptador) }\end{array}$ & $\begin{array}{l}\text { A Cabana do Pai } \\
\text { Tomás (adaptação } \\
\text { Clube do Livro; } \\
\text { 1969; adaptação de } \\
\text { Evangelista Prado) }\end{array}$ & $\begin{array}{l}\text { A Cabana do Pai } \\
\text { Tomás (tradução } \\
\text { Juruá Editora; 2012; } \\
\text { tradução de Nélia } \\
\text { Maria Pinheiro } \\
\text { Padilha von Tempski- } \\
\text { Silka) }\end{array}$ \\
\hline $\begin{array}{l}\text { "Why, laws me, } \\
\text { Missis!" said Chloe, } \\
\text { laughing again, "other } \\
\text { folks hires out der } \\
\text { niggers and makes } \\
\text { Money on 'em! Don't } \\
\text { keep sich a tribe eatin } \\
\text { 'em out of house and } \\
\text { home." }\end{array}$ & $\begin{array}{l}\text { - Ora, minha senhora, } \\
\text { muita gente ganha } \\
\text { dinheiro alugando } \\
\text { os escravos. Sam } \\
\text { contou-me que há, } \\
\text { em Louisville, alguns } \\
\text { doceiros precisando } \\
\text { de empregados. Pagam } \\
\text { quatro dólares por } \\
\text { semana. }\end{array}$ & $\begin{array}{l}\text { - Ora, minha senhora, } \\
\text { muita gente ganha } \\
\text { dinheiro, alugando } \\
\text { os escravos. Sam } \\
\text { contou-me que há, } \\
\text { em Louisville, alguns } \\
\text { doceiros precisando } \\
\text { de empregados. Pagam } \\
\text { quatro dólares por } \\
\text { semana. }\end{array}$ & $\begin{array}{l}\text { - Ora, vejam só, } \\
\text { patroa! - disse Cloé, } \\
\text { rindo novamente - } \\
\text { outras pessoas alugam } \\
\text { seus negros e fazem } \\
\text { dinheiro com eles! } \\
\text { Não conservam uma } \\
\text { gente como essa, se } \\
\text { preocupando com eles } \\
\text { fora de casa e do lar. }\end{array}$ \\
\hline
\end{tabular}


Cloé sugere à Sra. Shelby que ela a alugue como cozinheira para uma confeitaria, e utiliza-se da expressão eatin 'em out of bouse and home, que significaria algo como "levar à ruína, à miséria", "endividar". A tradução da Juruá transforma o significado da expressão, criando um sentido distinto que implicaria que, estando os escravos alugados, a Sra. Shelby - por ser diferente de outros donos de escravos, que não se importariam com os escravos, percebendo-os apenas como propriedades se preocuparia com eles, que estariam longe "de casa e do lar", ou seja, de sua esfera de influência e proteção. Dessa forma, enquanto no original Cloé usa o argumento financeiro para convencer sua patroa (estando alugada para trabalhar na confeitaria, ao invés de ser uma despesa para os ricos, porém endividados Shelby, Cloé poderia gerar lucros), na tradução a personagem procura apelar a elogios quanto à moral da patroa. Ao escolher essa linha interpretativa, a Juruá Editora adiciona nuances de sentido ao texto e suaviza a relação entre escrava e senhora, contrastando-a com outros relacionamentos semelhantes apresentados na obra, como o de Tomás com seu último dono, em que, ao invés de um espaço de negociação, reinava a brutalidade e a crueldade.

A adaptação da Edições Paulinas, por outro lado, mantém a questão do dinheiro, sendo seguida pelo Clube do Livro, sumarizando, além disso, muito da discussão. Mais do que tentar convencer a Sra. Shelby, Cloé lhe dá informações adicionais que falam por si mesmas.

Por fim, o trecho abaixo faz parte de uma carta que George Harris manda para um amigo. Ela trata justamente de sua identidade, e, por enfatizar questões raciais, e não religiosas, foi excluída da adaptação da Edições Paulinas, e, consequentemente, da adaptação do Clube do Livro:

Tabela 6: George manda uma carta para um amigo

\begin{tabular}{|l|l|l|l|}
\hline $\begin{array}{l}\text { Uncle Tom's Cabin } \\
\text { (original - 1852) }\end{array}$ & $\begin{array}{l}\text { A Cabana do Pai } \\
\text { Tomás (adaptação } \\
\text { Edições Paulinas; } \\
\text { 1964; sem indicação } \\
\text { de adaptador) }\end{array}$ & $\begin{array}{l}\text { A Cabana do Pai } \\
\text { Tomás (adaptação } \\
\text { Clube do Livro } ; \\
1969 ; \text { adaptação de } \\
\text { Evangelista Prado) }\end{array}$ & $\begin{array}{l}\text { A Cabana do Pai } \\
\text { Tomás (tradução Editora } 2012 ; \\
\text { tradução de Nélia } \\
\text { Maria Pinheiro Padilha } \\
\text { von Tempski-Silka) }\end{array}$ \\
\hline
\end{tabular}




\begin{tabular}{|c|c|c|c|}
\hline $\begin{array}{l}\text { "I feel somewhat at a } \\
\text { loss, as to my future } \\
\text { course. True, as you } \\
\text { have said to me, I } \\
\text { might mingle in the } \\
\text { circles of the whites, } \\
\text { in this country, my } \\
\text { shade of color is so } \\
\text { slight, and that of my } \\
\text { wife and family scarce } \\
\text { perceptible. Well, } \\
\text { perhaps, on sufferance, } \\
\text { I might. But, to tell } \\
\text { you the truth, I have } \\
\text { no wish to. }\end{array}$ & Trecho retirado & Trecho retirado & $\begin{array}{l}{[\ldots . .] \text { "Sinto-me de }} \\
\text { certa forma perdido, } \\
\text { no que diz respeito à } \\
\text { minha futura trajetória. } \\
\text { É verdade, como } \\
\text { você tem sempre } \\
\text { me dito, que posso } \\
\text { circular como se fora } \\
\text { um branco neste país; } \\
\text { a cor da minha pele } \\
\text { sendo tão clara, e a da } \\
\text { minha família quase } \\
\text { que imperceptível. } \\
\text { Bem: talvez com } \\
\text { algum sacrifício eu } \\
\text { consiga. Mas para falar } \\
\text { a verdade, não tenho } \\
\text { vontade de agir assim. } \\
\text { Minhas simpatias não } \\
\text { recaem sobre a raça } \\
\text { do meu pai, mas a da } \\
\text { minha mãe. Para ele, } \\
\text { eu não era nada mais } \\
\text { do que um belo cão } \\
\text { ou cavalo: para minha } \\
\text { pobre mãe, de coração } \\
\text { partido, eu era um filho; } \\
\text { [...] }\end{array}$ \\
\hline
\end{tabular}

Nessa passagem, George, que é mestiço, expõe os motivos pelos quais, apesar de sua pele clara, identifica-se como negro. Longe de confirmar, no entanto, a regra da gota de sangue única ou a separação racial nos EUA, este trecho evidencia que as identidades são construídas, e, portanto, o lugar do mestiço, mesmo na cultura norte-americana, não tem porque ser um não-lugar, como os estereótipos raciais desse país apontariam. As pessoas estariam livres para escolher sua identidade de acordo com suas experiências, do mesmo modo que George faz no trecho acima.

\section{CONSIDERAÇÕES FINAIS: IDENTIDADES LIMÍTROFES NA DIMENSÃO RACIAL E NA QUESTÃOO TRADUTÓRIA}

Ao longo da história dos Estudos da Tradução, a adaptação foi considerada uma prática subalterna. A ela são associadas características como simplificadora, 
infantil e manipuladora. No entanto, sob certas circunstâncias, essas mesmas qualidades são associadas à tradução. Os dois processos ora se aproximam, ora se afastam; por vezes suas fronteiras parecem estar claramente delimitadas, por vezes elas se confundem e tradução e adaptação adentram território alheio.

O relacionamento entre essas duas práticas não é simples ou estático. Mesmo casos prototípicos, como os apresentados neste artigo, apresentam desafios e questões que permanecem sem resposta. Como exemplo, temos um dos critérios mais comuns para a diferenciação entre tradução e adaptação: a integridade da obra. A tradução da Juruá Editora mantém todos os capítulos encontrados no texto original, e a adaptação da Edições Paulinas diminui a quantidade de capítulos quase pela metade; muitos teóricos afirmam que isso seria suficiente para que essa reescritura fosse classificada como adaptação, mas o modo como se chega a essa conclusão deixa dúvidas. Poderíamos nos perguntar, caso aceitássemos esse argumento, em que ponto poderíamos chamar uma obra de adaptação. Quantos capítulos, linhas, palavras retiradas seriam necessários para que uma reescritura fosse considerada adaptação? Não há, certamente, um limite preciso, absolutamente objetivo, que demarque a transição entre uma prática e outra, e ainda assim é inegável que, de um modo ou de outro, esses cortes realizados na obra tendem, convencionalmente, nos dias atuais, a serem considerados características prototípicas atribuídas aos textos publicados como adaptações, e não como traduções.

Dessa forma, o elemento "quantitativo" (a noção de integralidade do texto) é considerado, geralmente, um critério importante de distinção entre adaptação e tradução. No caso da tradução e das adaptações analisadas, a aceitação desses rótulos é quase instintiva, e a diferença gritante de tamanho dos textos é parte do que torna essa aceitação possível. O mesmo não pode ser dito dos critérios de fidelidade e de criatividade, tantas vezes relacionadas a traduções e adaptações, respectivamente. Nos casos apresentados, percebe-se que essas características não são, de fato, inerentes a essas práticas. A tradução da editora Juruá, que supostamente deveria ser fiel ao texto, apresenta soluções de tradução que poderiam facilmente ser classificadas como criativas, e possivelmente como estratégias adaptativas. A adaptação da Edições Paulinas, no extremo oposto, omite trechos como forma de lidar com elementos que pediriam por uma solução criativa da parte do adaptador e da editora. De certa forma, o fundamento da criatividade, pelos padrões tradicionais, se inverte nessas duas obras.

Outro critério de diferenciação que se prova ineficiente para delimitar tradução e adaptação seria o do público leitor e o quanto seus supostos interesses influenciariam as reescrituras. A Edições Paulinas é uma editora católica, e desde 
o início percebe-se que o público leitor pressuposto da Edições Paulinas seriam os católicos. E, seguindo a proposta dessa ideologia, a maioria das mudanças promovidas nessa reescritura tem o efeito de dar mais visibilidade e importância a questões relacionadas à religião cristã. $\mathrm{O}$ enredo tratando de Eliza e George Harris, de suas respectivas fugas, da fé de Eliza e da descrença de George, da violência que ele sofre e pratica, todos esses elementos são omitidos da obra, do modo como a história contada gira em torno de Tomás e sua ascensão moral até o martírio. As questões raciais levantadas pela obra original, bem como a problemática da escravidão, são colocadas em segundo plano, quando abordadas. No entanto, nada impediria leitores de outras religiões de ler e consumir a adaptação da Edições Paulinas, tal como ocorre, por exemplo, com romances espíritas.

O público leitor pressuposto da tradução da Juruá, por outro lado, parece ser mais amplo, num primeiro olhar: seria bem-vinda a leitura de qualquer pessoa interessada nos temas abordados pela obra, o que, em teoria, permitiria à reescritura uma maior liberdade de escolhas. Na prática, esses leitores pressupostos influenciam os caminhos que a tradução segue tanto quanto o público da Edições Paulinas, bem mais delimitado, consegue influenciar sua adaptação: eles seriam leitores mais educados, provavelmente ligados a discussões sobre raça e preconceito no Brasil, e isso leva a escolhas que seguem o politicamente correto de nosso tempo, muitas vezes suavizando a natureza da obra. Quando a tradução abandona essa postura, ela o faz propositalmente, e o choque causado por essa opção é calculado. Dessa forma, o pressuposto de que adaptações teriam um público leitor mais restrito e traduções teriam um público leitor amplo, tornando o público alvo um critério de diferenciação entre as duas práticas, prova-se insuficiente.

O caso da adaptação do Clube do Livro, no entanto, é o mais interessante dentre esses três textos, justamente pelo fato de essa editora não se incomodar em considerar esse público, ou mesmo a ideologia que advoga. O público leitor do Clube do Livro era imenso, geralmente formado por pessoas da classe média baixa, com pouca educação formal. Segundo Milton (2002), no início de seu período de atividades, na década de 40, o Clube do Livro era mais sério. No entanto, essa característica não parece ter sido mantida até a época em que foi lançado A Cabana do Pai Tomás: a versão do Clube do Livro é uma cópia quase idêntica da adaptação da Edições Paulinas, com as únicas diferenças sendo algumas atualizações de vocabulário, algumas mudanças de pontuação e o corte de trechos. Não há a possibilidade de que as opções utilizadas sejam as mesmas por coincidência: aceitar a possibilidade de que duas reescrituras sejam tão idênticas, da pontuação à escolha lexical, do nível da linguagem a quais elementos são retirados, ou seja, aceitar que 
o produtor de dois processos transformativos por definição, que contariam com subjetividades distintas, possam chegar exatamente ao mesmo lugar, seria aceitar que o processo de tradução, e também de adaptação, seriam exatos e objetivos, que tradutor e adaptador são apenas pontes passivas e que não entram em jogo interesses de editoras e sociedades. Só nos restaria especular o motivo por trás dessa cópia: o Clube do Livro cometeu plágio, ou comprou a versão da Edições Paulinas? Ele fez isso apenas por a versão da Edições Paulinas já estar disponível, ou haveria algum outro motivo para essa versão específica ter sido escolhida? É possível que, dado o ambiente político e a moral conservadora da época, o Clube do Livro tenha considerado simplesmente mais seguro se valer de uma versão já aprovada pelo mercado editorial e público leitor da época.

Apesar da diferença pautada pela questão da integralidade da tradução (e sua ausência na adaptação), as outras duas reescrituras analisadas, a tradução da Juruá Editora e a adaptação da Edições Paulinas, não se apresentam como próximas apenas pela falta de um método claro de diferenciação que não se paute apenas na questão quantitativa: muitas vezes, as escolhas selecionadas pelas duas versões coincidem, mostrando-se ajustáveis às duas formas.

Uma dessas escolhas é a uniformização da linguagem dos personagens. Tanto tradução quanto adaptação escolhem homogeneizar o linguajar usado tanto por alguns personagens, que costuma ser "não padrão" para denotar a ausência de educação formal, quanto pelos quaker, que escolhem um registro informal por razões ideológicas, e pelos antagonistas, que em geral utilizam expressões pejorativas e um falar rude para espelhar suas falhas morais. A tradução justifica essa escolha pela manutenção da fluidez do texto: uma representação escrita de diferenças dialetais muitas vezes pode sugerir, a muitos leitores, uma leitura truncada, e seria em função dessa dificuldade que a tradutora opta por preservar a norma padrão para todos os personagens.

A adaptação da Edições Paulinas também uniformiza o modo de falar dos personagens, mas não justifica sua escolha. O mais provável é que ela compartilhe da tradição brasileira da hipercorreção, que ocorre em vários livros, em que a linguagem marcada é transformada na linguagem padrão, não necessariamente por ignorância das nuances adicionadas aos textos por tradutores, adaptadores e editoras, mas pelo possível julgamento negativo por parte dos leitores mais conservadores.

Um dos pontos em que as duas reescrituras divergem é nas notas explicativas ao longo do texto. A tradução da Juruá apresenta 96 delas, e a adaptação, nenhuma. Poder-se-ia levantar duas hipóteses para explicar essa diferença gritante: a tradução da Juruá seria paternalista, dando a seus leitores informações que seriam desnecessárias 
ou de fácil localização, ou a adaptação da Edições Paulinas é manipuladora, transformando o texto a tal ponto que nenhuma nota se faz necessária.

É verdadeiro, e mesmo evidente, que a adaptação e a tradução transformam o original: essa mudança é inerente a esses processos de modo que muitas das características a eles atribuídas, como fidelidade à tradução e criatividade à adaptação, não o são de fato. No entanto, se a adaptação da Edições Paulinas foi criada de modo a manipular o leitor, a tradução da Juruá também o faz, pois ambas foram concebidas e executadas com objetivos e interesses específicos em mente. A questão das notas do tradutor, assim como quais elementos são eliminados, refletem, nas duas reescrituras, um aspecto histórico de produção: a versão da Juruá foi publicada em um contexto em que notas do tradutor, prefácios e introduções, três elementos presentes na obra, são marcas de uma tradução "séria", imagem que a editora procura associar a si mesma. A versão da Edições Paulinas muito provavelmente não tinha essa preocupação, e agiu de acordo.

Outro aspecto que as obras não compartilham é a preocupação em relação às questões raciais. Por conta de seu objetivo explícito de propagar a religião católica, a maioria das referências a preconceitos de raça, ao tratamento desumano dos escravos e à luta pela liberdade são retiradas na adaptação da Edições Paulinas, para não retirar o foco do aspecto religioso. $\mathrm{O}$ que resta, correspondente à forma como são apresentadas as opções tradutórias de termos como nigger, black e negro, demonstra uma perspectiva descompromissada com a questão racial: não há uma preocupação em ser politicamente correto ou em ofender os leitores, possivelmente porque, sendo essa adaptação anterior à tomada de força dos movimentos negros no Brasil, que Bernd (1988) localiza em 1969, e do Estatuto da Igualdade Racial, provavelmente não havia uma discussão arraigada sobre o lugar do negro na sociedade e a discriminação, e o preconceito racial pareceria uma lenda, enquanto a ideia de que o Brasil seria uma nação desprovida de preconceito racial ainda reinava absoluta. A adaptação também acrescenta, em algumas ocasiões, termos como "negro" e "preto" no lugar de pronomes e nomes próprios, sem motivo aparente, provocando um afastamento do negro para o lugar do Outro, uma desumanização dos personagens negros. Também é digno de nota que, em dados momentos, termos que indicam uma fração de mestiçagem são retirados, sendo substituídos por palavras que não carregam nenhum significado racial por si mesmas, como a troca de mulatto por "escrava".

Essas mudanças possivelmente indicam uma subjetividade contrária à miscigenação na obra, embora provavelmente não por motivos como os apresentados por Munanga (2004). Mais do que se opor à mestiçagem, a adaptação busca apagá- 
la, separando, de forma incisiva, brancos e negros na cultura norte-americana. Essa postura, dada a forma como se apresenta ao longo da adaptação, possivelmente reflete o estado em que as discussões raciais estariam à época da publicação dessa versão: os movimentos negros no Brasil ainda não haviam conquistado suas vitórias mais significativas, havia um clima conservador na política, e não havia uma preocupação em se combater, ou pelo menos esconder, expressões e posicionamentos racistas, ao mesmo tempo em que se propagava a ideia de que o Brasil, não os EUA, seria a nação que carregaria a miscigenação como patrimônio cultural: daí o apagamento de identidades entre as fronteiras branco/negro na adaptação.

Essa perspectiva mostra-se especialmente interessante quando levamos em consideração a imagem de mestiço apresentada no original: se por um lado, no livro, a mestiçagem é claramente ligada ao abuso sexual das escravas, por outro lado, a narrativa discorda de Munanga (2004) quanto à identidade negra desses mestiços: muitos deles, como as personagens Rosa e Jane, permanecem confortavelmente numa fronteira entre as raças; outros, como George Harris, escolhem abraçar uma identidade negra em razão de suas experiências pessoais. $\mathrm{O}$ fato de a adaptação da Edições Paulinas optar por retirar quase que inteiramente essa representação de mestiçagem na cultura estadunidense parece demonstrar que a ideologia da democracia racial e o mito de origem relacionado à miscigenação seriam tidos como um aspecto unicamente brasileiro.

No oposto desse espectro, está a tradução da Juruá Editora, que se alinha à tese do pluriculturalismo e que, coincidentemente, publica sua tradução de Uncle Tom's Cabin após o Estatuto da Igualdade Racial, numa era em que as discussões raciais estão em pauta no Brasil. As representações de mestiços, nessa tradução, são tão abundantes quanto no original, no entanto, o que se observa é que, em sua maioria, essas representações carregam em si um aspecto diferente: muitos dos termos relacionados à miscigenação são utilizados em contextos, se não negativos, críticos à identidade do mestiço; também são utilizados os estrangeirismos quadroon e mulatto, transportando a realidade da miscigenação para longe do contexto brasileiro, fazendo escolhas que se alinham à política do pluriculturalismo que a editora adota explicitamente em seu site.

E, de acordo com essa ideologia, a tradução da Juruá Editora toma muito cuidado em sua reescritura com a representação dos personagens negros, especialmente na tradução de termos com alto teor pejorativo, como o frequente nigger, que só é traduzido por termos igualmente degradantes quando pronunciados de forma irônica, quando o termo é utilizado por outros personagens negros, e quando o personagem que fala é tal que não há maneira de o público simpatizar ou 
identificar-se com ele. Outro recurso que a tradução usa é a suavização, como no caso citado anteriormente em que o termo grotesque é amenizado, e o termo wild é retirado, suavizando, nessa ocorrência específica, mas também posteriormente no texto, a possível percepção que os leitores têm da autora (tomada como a narradora), atenuando muitos dos preconceitos e estereótipos propagados por ela e dando ênfase ao seu aspecto mais louvável: sua determinação em combater a escravidão.

As escolhas que as editoras fazem sobre como abordar - ou deixar de abordar - a questão racial em suas reescrituras reflete, em certa medida, a forma como elas entendem a identidade afrodescendente: enquanto a Juruá parece abraçar essa identidade, traduzindo termos raciais de modo a apontar para diversas instâncias identitárias, embora não deixe de mostrar-se crítica a elas (como no caso de termos que indicam miscigenação), a Edições Paulinas opta por marcar a separação racial, chegando inclusive a acentuá-la, ao mesmo tempo em que retira da adaptação trechos que poderiam indicar as diferentes nuances que se fazem presentes numa discussão dessas questões.

Mas não são apenas as editoras que marcam o desafio, o esforço e a dificuldade da construção de uma identidade racial. Na própria obra de Stowe essa luta fica marcada não só pelos monólogos de vários personagens sobre o assunto, ou pelas observações do narrador: o uso dos termos marcadamente raciais funciona de modo a construir uma identidade negra, que, ao longo da obra, muda por razões internas e externas. Pode-se observar isso no modo como a quantidade de termos raciais pejorativos e desumanizadores aumentam ao longo do romance, conforme decaem as condições a que os escravos estão sujeitados. Aumenta também, ao longo da obra, o número de escravos que utilizam esses termos pejorativos em referência a si mesmos e a outros escravos, sugerindo que o ambiente em que vivem moldou sua identidade de maneira negativa. Isso só se inverte com o final otimista da obra, em que George Harris - personagem que superou a escravidão - discorre sobre si mesmo, sobre sua família e sua identidade racial usando termos neutros e positivos.

Dentre as reescrituras analisadas, a da Juruá foi a que adotou essa mesma postura da obra original, de forma que a própria linguagem das personagens, em sua tradução, funciona para reforçar a decadência moral do sistema escravagista. A adaptação da Edições Paulinas, por outro lado, não só retira a maior parte da narrativa centrada nas questões raciais, como retira as nuances acrescentadas ao original pelo uso estratégico de termos raciais marcados em circunstâncias específicas.

Provavelmente, essas diferenças de postura estão mais relacionadas com o contexto histórico em que foram produzidas do que com os processos de adaptação e tradução em si. Hoje, quando existe no público geral uma consciência 
e interesse maior por questões raciais, seria improvável que uma adaptação de Uncle Tom's Cabin dirigida ao público brasileiro omitisse as questões raciais presentes na obra, da mesma forma que uma tradução de Uncle Tom's Cabin publicada nos anos 60 provavelmente não forneceria a seus leitores tantas explicações sobre o texto. E essas duas reescritas, embora apresentem diferenças significativas, parecem se aproximar em diversas ocasiões, pelos recursos de que se utilizam, demonstrando que a tese de Krebs (2012), de que as duas práticas não apresentariam diferenças intrínsecas, não é infundada.

No entanto, ainda que as versões aqui analisadas representem exemplos prototípicos de tradução e de adaptação, os limites qualitativos entre essas práticas não são necessariamente evidentes, o que não deve significar a inexistência de tais limites. Assim, por exemplo, é necessário reconhecer uma diferença entre o traduzir e o adaptar que exerce influências de naturezas diversas sobre as relações entre leitores e textos. Se, por um lado, atualmente, todo livro publicado como adaptação já sugere ao leitor alguma forma de transformação legitimada pela editora, e que não se espera encontrar em uma obra publicada como tradução (ainda que isso não seja absolutamente improvável de acontecer), por outro lado, a expectativa que se cria, junto ao leitor, de que a tradução é a representação mais fidedigna do texto original, oferece as condições propícias para a promoção de leituras não menos desinteressadas ou orientadas por determinadas perspectivas ideológicas, sem que isso acarrete alguma ruptura com o texto original.

A tradução pode produzir efeitos de leitura tão ou mais eficazes que os proporcionados por uma obra publicada como adaptação, uma vez que, sendo alicerçada sobre o discurso da fidelidade, uma obra oferecida como tradução permite veicular interpretações que não necessariamente espelham, na mesma proporção, as relações ideológicas suscitadas no texto original. Assim, embora em um grande número de casos a tradução possa ser realmente considerada mais próxima ao texto fonte em sua integralidade do que muitas adaptações, a tradução não deixa de exercer o poder de demarcar certa visão de mundo capaz de amparar e até de fortalecer discursos em torno da construção/veiculação de (novas) identidades sem que esse gesto seja necessariamente visto como algo antiético, ou mesmo como uma impropriedade.

\section{REFERÊNCIAS BIBLIOGRÁFICAS}

AMORIM, L. M. (2005). Tradução e adaptação: encruzilhadas da textualidade em Alice in Wonderland, de Lewis Carrol, e Kim, de Rudyard Kipling. São Paulo: Editora UNESP. 
AZENHA, J.; MOREIRA, M. (2012). Translation and Rewriting: Don't Translators 'Adapt' When They 'Translate'? In: RAW, L. (Org.). Translation, Adaptation and Transformation. Continuum: Nova York. pp. 302-379.

BERND, Z. (1988) O que é negritude. São Paulo: Brasiliense.

BERTIN, M. R. (2011). Tales from Shakespeare no Brasil: traduções e adaptações do conto "The Tempest" endereçadas ao leitor infanto-juvenil. Caderno de Literatura em Tradução, vol.12, Especial Infantil, p. 47-70.

FERREIRA, E. P. ; SILVA, K.H.S. (2011). Edgar Allan Poe em português: os limites entre tradução e adaptação. Domínios de Linguagem, vol. 5, n. 3, p. 20-37.

KREBS, K. (2012). Translation and Adaptation - Two Sides of an Ideological Coin. In: RAW, L. (Org.). Translation, Adaptation and Transformation. Continuum: Nova York. pp. 226-274.

MAGNOLI, D. (2009). Gota de sangue: história do pensamento racial. São Paulo: Contexto.

MILTON, J. (2002). O Clube do Livro e a Tradução. Bauru: EDUSC.

MILTON, J. (2009). Translantion Studies and Adaptation Stuides. In: Anthony Pym \& Alexander Perekrestenko (Org.). Translation Research Projects 2. Tarragona, Espanba: Intercultural Studies Group, Universitat Rovira i Virgili, v.2, pp.58-66.

MUNANGA, K. (2004). Rediscutindo a mestiçagem no Brasil: identidade nacional versus identidade negra. São Paulo: Autêntica.

RODRIGUES, C. C. (2002). Tradução e adaptação: sentidos na história. Estudos Linguísticos, São Paulo, v. 31, p. 1-6.

STOWE, H. B. (1964). A Cabana do Pai Tomás. São Paulo: Edições Paulinas.

STOWE, H. B. (1969). A Cabana do Pai Tomás. Adaptação de Evangelista Prado. São Paulo: Clube do Livro.

STOWE, H. B. (2012). A Cabana do Pai Tomás - A Vida Entre os Humildes. Tradução de Nélia Maria Pinheiro Padilha von Tempski-Silka. Curitiba: Juruá Editora.

STOWE, H. B. (1852). Uncle Tom's Cabin or Life among the Lowly. Disponível em < "http:// www.gutenberg.org/ebooks/203"> . Acesso em: 20 mai. 2013.

Recebido: 25/06/2015

Aceito: 04/11/2015 